\title{
A SYSTEMATIC CLINICAL REVIEW OF PRENATALLY DIAGNOSED TETRASOMY 9p
}

\author{
Vinkšel M, Volk M, Peterlin B, Lovrecic L* \\ *Corresponding Author: Luca Lovrecic, M.D., Ph.D., Assistant Professor, Clinical Institute of Medi- \\ cal Genetics, University Medical Centre Ljubljana, Zaloska cesta 002, SI-1000 Ljubljana, Slovenia. Tel: \\ +386-1-522-6057. Fax: +386-1-540-1137. E-mail: luca.lovrecic@kclj.si
}

\begin{abstract}
Tetrasomy 9p was first described in 1973 and approximately 68 cases with a variable phenotype have been reported to date with 22 of them being detected prenatally. The objective of this study was to review prenatally-reported cases of tetrasomy $9 p$ thus far and to identify ultrasound phenotypes that may be suggestive of this specific syndrome. A PubMed database search was done in February 2018 without any restriction of publication date or journals, with the use of the following keywords: tetrasomy $9 p$, tetrasomy $9 \mathrm{p}$ prenatal, mosaic tetrasomy $9 \mathrm{p}$, mosaic tetrasomy 9p prenatal, isochromosome $9 \mathrm{p}$, duplication $9 \mathrm{p}$ prenatal, trisomy 9p prenatal. Reported cases were included if the clinical presentation and diagnostic approach of each case was clearly described. The most common characteristics of prenatally-detected tetrasomy $9 p$ are intrauterine growth retardation (IUGR, 57.0\%), central nervous system (CNS) abnormalities (59.0\%), skeletal anomalies $(29.0 \%)$, genitourinary and renal anomalies $(29.0 \%)$ and cardiac defects $(29.0 \%)$. The phenotypic spectrum of tetrasomy $9 p$ is rather unspecific as these findings are commonly associated with other chromosome anomalies, as well as microdeletion/microduplication or monogenic syndromes. The combination of early fetal morphology and diagnostic genetic testing enables a definite tetrasomy $9 p$ diagnosis and effective further pregnancy management.
\end{abstract}

Keywords: Array comparative genomic hybridization (aCGH); Chromosome anomalies; Molecular karyotyping; Prenatal genetic diagnostics; Tetrasomy 9p.

Clinical Institute of Medical Genetics, University Medical Centre Ljubljana, Ljubljana, Slovenia

\section{INTRODUCTION}

Tetrasomy $9 \mathrm{p}$ is a rare chromosomal abnormality characterized by the presence of four copies of the short $\mathrm{p}$ arm of chromosome 9 . Occasionally, a minute portion of the long $\mathrm{q}$ arm is duplicated as well. The common mechanism associated with formation of tetrasomy $9 p$ seems to be meiosis II non disjunction of maternal origin, followed by meiotic or postmeiotic mitotic misdivision or recombination leading to duplication with subsequent loss of the $q$ arm of chromosome 9 [1].

Tetrasomy $9 \mathrm{p}$ was first described by Ghymers et al. [2] in 1973 in a child with multiple abnormalities, where classic karyotype analysis revealed tetrasomy $9 p$ in lymphocytes, but not in fibroblasts. The first prenatal case of tetrasomy 9p was published by Schaefer et al. [3] in 1991, where the chromosomal abnormality was detected in cord blood lymphocytes in a fetus with multiple anomalies, including dolichocephaly with hydrocephalus, possible spinal dysraphism, absent kidneys and bladder, severe oligohydraminos and intrauterine growth retardation.

Especially in the later years, the detection rate of tetrasomy $9 p$ increased with better fetal monitoring and more accessible prenatal diagnostics. Fourteen cases were reported in last 3 years [4-7], detected using microarrays in comparison with 53 cases reported from 1973 to 2015 using GTG banding and/or fluorescent in situ hybridization (FISH), analysis [1-3,8-52].

The objective of this review was to highlight the importance of early fetal ultrasound screening in identifying rare chromosomal abnormalities and to present the array comparative genomic hybridization (aCGH) as a valuable clinical diagnostic tool that allows rapid and precise identification of chromosomal abnormalities. The purpose of this study was a comprehensive review of the 
literature regarding prenatal tetrasomy $9 \mathrm{p}$ syndrome with comparison of fetal abnormalities seen in different stages of fetal development. In addition, the comparison of mosaic vs. non mosaic forms of tetrasomy $9 p$ is presented, with the focus on the differences in the clinical presentation between both groups, correlation of the level of mosaicism with the phenotype and diagnostic challenges related to mosaic cases.

\section{MATERIALS, METHODS AND DATA SOURCE}

Literature Search. A PubMed database search was performed without any publication date or journal restriction with the following key words: tetrasomy $9 p$, isochro-mosome 9p, mosaic tetrasomy 9p, tetrasomy 9p prenatal, duplication 9p prenatal and trisomy 9p prenatal. All cases describing a prenatally-detected tetrasomy $9 p$ were hand-searched for relevant information with the focus on the gestational age at the time of diagnosis, the type(s) and results of genetic diagnostic tests, ultrasound findings, pregnancy outcome and confirmatory studies. Secondly, we chose the key words trisomy $9 p$ and duplication $9 p$ to divide and compare the severity of the clinical picture, depending on the 9p copy number/gene dosage effect (trisomy $9 \mathrm{p}$ vs. tetrasomy $9 \mathrm{p}$ ).

Methodology. In addition to previously reported cases of tetrasomy $9 \mathrm{p}$, we added a prenatally discovered case of tetrasomy $9 p$ at the Clinical Institute of Medical Genetics, University Medical Centre Ljubljana (UMCL), Ljubljana, Slovenia. It was detected using microarray analysis (60K aCGH; Agilent Technologies, Santa Clara, CA, USA), after increased nuchal translucency (NT) of $4.1 \mathrm{~mm}$ at the gestational age $12^{+0}$ weeks and chorionic villus sampling. Additionally, the GTG banding and FISH analysis with probes Vysis TelVyson 9p SG, TelVyson 9q SO and CEP 9 Saq (Abbott Molecular; Abbott Laboratories, Chicago, $\mathrm{IL}$, USA), were used for confirmation of tetrasomy $9 \mathrm{p}$. Additional anomalies including facial dysmorphism, cleft lip/palate and genitourinary abnormalities were detected with ultrasound at the gestational age $15^{+1}$ weeks.

Table 1. Prentally detected abnormalities of 22 cases of tetrasomy 9p.

\begin{tabular}{|c|c|c|c|c|c|c|c|c|}
\hline Refs. & $\begin{array}{c}\text { Facial } \\
\text { Dysmorphism }\end{array}$ & $\begin{array}{c}\text { Cleft Lip/ } \\
\text { Palate }\end{array}$ & IUGR & $\begin{array}{c}\text { CNS } \\
\text { Anomalies }\end{array}$ & $\begin{array}{c}\text { Cardiac } \\
\text { Anomalies }\end{array}$ & $\begin{array}{c}\text { Genitourinary } \\
\text { Tract } \\
\text { Anomalies }\end{array}$ & $\begin{array}{c}\text { Skeletal/ } \\
\text { Limb } \\
\text { Anomalies }\end{array}$ & $\begin{array}{c}\text { Amniotic Fluid } \\
\text { Volume } \\
\text { Anomalies }\end{array}$ \\
\hline Our case & {$[+]$} & {$[+]$} & {$[-]$} & {$[-]$} & {$[-]$} & {$[+]$} & {$[+]$} & {$[-]$} \\
\hline$[5]$ & {$[+]$} & {$[+]$} & {$[-]$} & {$[-]$} & {$[-]$} & {$[-]$} & {$[+]$} & {$[-]$} \\
\hline$[5]$ & {$[+]$} & {$[-]$} & {$[+]$} & {$[+]$} & {$[-]$} & {$[+]$} & {$[-]$} & {$[-]$} \\
\hline$[6]$ & {$[+]$} & {$[-]$} & {$[+]$} & {$[+]$} & {$[-]$} & {$[-]$} & {$[+]$} & {$[+]$} \\
\hline$[52]$ & {$[-]$} & {$[-]$} & {$[-]$} & {$[-]$} & {$[+]$} & {$[-]$} & {$[-]$} & {$[-]$} \\
\hline$[51]$ & {$[-]$} & {$[-]$} & {$[-]$} & {$[-]$} & {$[-]$} & {$[-]$} & {$[+]$} & {$[-]$} \\
\hline$[4]$ & {$[-]$} & {$[-]$} & {$[+]$} & {$[-]$} & {$[-]$} & {$[-]$} & {$[-]$} & {$[-]$} \\
\hline$[45]$ & {$[+]$} & {$[+]$} & {$[-]$} & {$[+]$} & {$[-]$} & {$[+]$} & {$[+]$} & {$[-]$} \\
\hline$[39]$ & {$[+]$} & {$[+]$} & {$[+]$} & {$[+]$} & {$[+]$} & {$[+]$} & {$[+]$} & {$[+]$} \\
\hline$[34]$ & {$[-]$} & {$[-]$} & {$[-]$} & {$[-]$} & {$[-]$} & {$[-]$} & {$[-]$} & {$[-]$} \\
\hline$[46]$ & {$[+]$} & {$[+]$} & {$[+]$} & {$[-]$} & {$[-]$} & {$[-]$} & {$[+]$} & {$[+]$} \\
\hline$[40]$ & {$[+]$} & {$[-]$} & {$[-]$} & {$[+]$} & {$[+]$} & {$[-]$} & {$[+]$} & {$[+]$} \\
\hline$[37]$ & {$[-]$} & {$[-]$} & {$[-]$} & {$[+]$} & {$[-]$} & {$[+]$} & {$[-]$} & {$[-]$} \\
\hline$[47]$ & {$[-]$} & {$[+]$} & {$[-]$} & {$[+]$} & {$[-]$} & {$[-]$} & {$[+]$} & {$[-]$} \\
\hline$[33]$ & {$[-]$} & {$[-]$} & {$[+]$} & {$[+]$} & {$[-]$} & {$[-]$} & {$[-]$} & {$[-]$} \\
\hline$[38]$ & {$[-]$} & {$[+]$} & {$[-]$} & {$[-]$} & {$[+]$} & {$[-]$} & {$[+]$} & {$[-]$} \\
\hline$[38]$ & {$[-]$} & {$[+]$} & {$[+]$} & {$[+]$} & {$[-]$} & {$[-]$} & {$[-]$} & {$[-]$} \\
\hline$[1]$ & {$[-]$} & {$[+]$} & {$[+]$} & {$[-]$} & {$[-]$} & {$[-]$} & {$[-]$} & {$[-]$} \\
\hline$[1]$ & {$[-]$} & {$[-]$} & {$[+]$} & {$[-]$} & {$[-]$} & {$[-]$} & {$[+]$} & {$[+]$} \\
\hline$[32]$ & {$[-]$} & {$[+]$} & {$[-]$} & {$[+]$} & {$[+]$} & {$[+]$} & {$[+]$} & {$[-]$} \\
\hline$[3]$ & {$[-]$} & {$[-]$} & {$[+]$} & {$[+]$} & {$[-]$} & {$[+]$} & {$[-]$} & {$[+]$} \\
\hline$[15]$ & {$[-]$} & {$[-]$} & {$[-]$} & {$[+]$} & {$[-]$} & {$[-]$} & {$[-]$} & {$[-]$} \\
\hline
\end{tabular}

IUGR: intrauterine growth retardation; CNS: central nervous system; [+]: present; [-]: not present. 


\section{RESULTS}

A total of 85 articles were matched to selected key words. After applying selected criteria, 21 cases of prenatally detected tetrasomy $9 p$ in 18 different publications remained for detailed analysis. We added our prenatal case, resulting in 22 cases altogether. Of these, 15 cases were related to full tetrasomy $9 p$ and seven cases were a mosaic form of tetrasomy $9 p$. A further four publications were identified describing trisomy $9 p$ detected prenatally and were suitable for comparison of tetrasomy $9 p$ and trisomy 9p phenotype [53-56].

Altogether, most of the reported cases of tetrasomy $9 \mathrm{p}$ were associated with severe congenital abnormalities. The most common prenatally detected features of tetrasomy 9p were central nervous system (CNS) abnormalities $(13 / 22)$ (our case $[3,5,7,15,32,33,37-40,45,47]), \mathrm{limb} /$ skeletal malformations (11/22) (our case $[1,5,7,32,38$ $40,45,47,51)]$, intrauterine growth retardation (IUGR) (10/22) $[1,3-5,7,33,38,39,46]$, cleft lip and/or palate $(10 / 22)$ (our case $[1,5,32,38,39,45-47)]$, and facial dysmorphism $(8 / 22$ ) (our case $[5,7,39,40,45,46)]$. All the details and less common anomalies are presented in Tables 1 and 2.

The type of fetal anomalies were further analyzed related to fetal gestational age at their discovery (details are presented in Table 3). A total of six cases of tetrasomy $9 p$ were detected in the first trimester based on abnormal

Table 2. Detailed karyotype results in prenatally detected cases of tetrasomy 9p.

\begin{tabular}{|c|c|c|c|}
\hline Refs. & Karyotype & Molecular Karyotype & \begin{tabular}{|l|} 
Confirmatory \\
Studies \\
\end{tabular} \\
\hline $\begin{array}{l}\text { Our } \\
\text { case }\end{array}$ & CVS: $47,+\mathrm{i}(9 \mathrm{p})(\mathrm{q} 13)=100.0 \%$ [Figure $1(\mathrm{a})$ and $1(\mathrm{~b})]$ & $\begin{array}{l}\text { arr[hg19] 9p24.3p13.2(204,193- } \\
\text { 38,815,475) } \times 4 \text { [Figure 1(c)] }\end{array}$ & muscle: $100.0 \%$ \\
\hline$[51] ?$ & CVS: $+\mathrm{i}(9 \mathrm{p})=100.0 \%$ & - & no \\
\hline [1] & CVS: $47, \mathrm{XY},+\mathrm{i}(9 \mathrm{p})=100.0 \% ; \mathrm{AC}: 47, \mathrm{XY},+\mathrm{i}(9 \mathrm{p})$ & - & no \\
\hline [4] & CVS: $47, \mathrm{XY},+\mathrm{i}(9 \mathrm{p})(\mathrm{q} 12)=100.0 \% ; \mathrm{AC}: 47, \mathrm{XY},+\mathrm{i}(9 \mathrm{p})(\mathrm{q} 12)=100.0 \%$ & - & \\
\hline [37] & CVS: $47, \mathrm{XY},+\mathrm{i}(9 \mathrm{p})(\mathrm{q} 12)=100.0 \% ; \mathrm{AC}: 47, \mathrm{XY},+\mathrm{i}(9 \mathrm{p})(\mathrm{q} 12)=100.0 \%$ & - & no \\
\hline [5] & CVS: $+\mathrm{i}(9 \mathrm{p})=100.0 \% ; \mathrm{AC}:+\mathrm{i}(9 \mathrm{p})=100.0 \%$ & $\begin{array}{l}\text { arr[hg19] 19p24.3q11(214,367- } \\
39,816,368) \times 4\end{array}$ & liver: $100.0 \%$ \\
\hline [45] & AC: $47, X Y,+i(9 p)=100.0 \%$ & - & no \\
\hline [39] & AC: $47, \mathrm{XY},+\mathrm{i}(9 \mathrm{p})(\mathrm{q} 13)=100.0 \%$ & - & no \\
\hline [46] & AC: $47, X Y,+i(9 p)=100.0 \%$ & - & no \\
\hline [47] & AC: $47, \mathrm{XX},+\mathrm{i}(9 \mathrm{p})=100.0 \%$ & - & $\begin{array}{l}\text { blood: } 95.0 \% \\
\text { cord blood: } \\
85.0 \%\end{array}$ \\
\hline [38] & AC: $47,+i(9 p)=96.3 \%$ & - & no \\
\hline [38] & $\mathrm{AC}: 47,+\mathrm{i}(9 \mathrm{p})=100.0 \%$ & - & $\begin{array}{l}\text { cord blood, } \\
\text { lung, placenta: } \\
100.0 \%\end{array}$ \\
\hline [1] & AC: $47, \mathrm{XY},+\mathrm{i}(9 \mathrm{p})=96.7 \%$ & - & no \\
\hline [32] & $\mathrm{AC}: 47,+\mathrm{i}(9 \mathrm{p})=100.0 \%$ & - & no \\
\hline [15] & $\mathrm{AC}: 47, \mathrm{XY},+\mathrm{i}(9 \mathrm{p})=100.0 \%$ & - & no \\
\hline [34] & $\begin{array}{l}\text { AC: } 47, X X,+i(9 p)(q 12)=20.0 \% ; \\
\text { Repeat AC: } 47, X X,+i(9 p)(q 12)=16.7 \%\end{array}$ & & $\begin{array}{l}\text { skin, lung: } \\
0.0 \% ; \text { cord } \\
\text { blood: } 48.0 \%\end{array}$ \\
\hline [5] & $\mathrm{AC}:+\mathrm{i}(9 \mathrm{p})=72.0 \%$ & - & fetal lung \\
\hline [6] & AC: $47, X X,+i(9 p)(q 12)=100.0 \%$ & 9p24.3-p13.1 (38,55 Mb) & no \\
\hline [4] & $\begin{array}{l}\text { AC: } 47, \mathrm{XX},+\mathrm{i}(9 \mathrm{p})(\mathrm{q} 12)=21.4 \% ; \text { Repeat } \mathrm{AC}: 47, \mathrm{XX}, \mathrm{i}(\mathrm{p})(\mathrm{q} 21.11)=16.7 \% ; \\
\text { FISH (on cultured amniocytes): } 47, \mathrm{XX},+\mathrm{i}(9 \mathrm{p})(\mathrm{q} 21.11)=47.1 \%\end{array}$ & 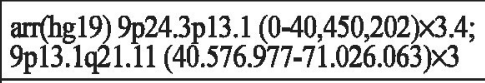 & \begin{tabular}{|l|} 
fetal blood: \\
$32.5 \%$ \\
\end{tabular} \\
\hline [52] & AC: $47, \mathrm{XX},+\mathrm{i}(9 \mathrm{p})(\mathrm{q} 12)=15.8 \%$; Cord blood: $47, \mathrm{XX},+\mathrm{i}(9 \mathrm{p})=59.7 \%$ & - & $\begin{array}{l}\text { skin: } 24.0 \% \text {; } \\
\text { lung: } 16.0 \% \\
\end{array}$ \\
\hline [33] & $\mathrm{AC}: 47, \mathrm{XX},+\mathrm{i}(9 \mathrm{p})(\mathrm{q} 13)=50.0 \%$; Cord blood: $47, \mathrm{XX},+\mathrm{i}(9 \mathrm{p})(\mathrm{q} 13)=25.0 \%$ & - & \begin{tabular}{|l} 
peripheral \\
blood: $75.3 \%$ \\
\end{tabular} \\
\hline [3] & Cordocentesis: $47, \mathrm{XX},+\mathrm{i}(9 \mathrm{p})=100.0 \%$ & - & skin: $100.0 \%$ \\
\hline
\end{tabular}

CVS: chorionic villus sampling; AC: amniocentesis; FISH: fluoresent in situ hybridization. 
ultrasound assessment. The most common phenotypic feature was increased NT (4/6) (our case [5,39,45]), usually accompanied by at least one more anomaly (cleft lip and/or palate, skeletal abnormalities, IUGR, and facial dysmorphism). A single case presented with isolated increased NT only (our case). In the latter, chorionic villus sampling was performed after genetic counseling. Microarray analysis detected a tetrasomy 9p with 38.6 Mb four copies of the region 9p24.3p13.2 (arr[GRCh37]9p24. 3p13.1(204193_38815475) ×4). The GTG banding and FISH analysis of 35 metaphase spreads revealed a pseudoisodicentric chromosome 9 consisting of the two $p$ arms, two centromere regions and two $q$ arm segments with a breakpoint at 9q13 (47,+psu idic(9)(q13) [Figure 1(A-C)].

In 10 cases of tetrasomy $9 p$, the abnormal ultrasound findings were reported in the second trimester. The most common fetal anomalies were CNS abnormalities (8/10) $[5,7,15,32,33,37,39,45]$, genitourinary tract anomalies $(6 / 10)[5,32,37,39,45]$, skeletal/limb abnormalities $(5 / 10)$ (our case) and facial dysmorphism (5/10) (our case [5,7,39, 45]). Additional anomalies were discovered in less than five cases. An additional three cases were identified only after a third trimester ultrasound scan, presenting with IUGR and additional CNS and skeletal/limb abnormalities. For the remaining cases it was not possible to determine the precise time of the prenatal diagnosis (PND).

When comparing the genotype-phenotype correlation in the group of mosaic (seven cases) $v s$. full tetrasomy $9 p$ ( 15 cases), less severe phenotypes were reported in mosaic
Table 4. Pregnancy outcome after the prenatal diagnosis of tetrasomy $9 \mathrm{p}$.

\begin{tabular}{|l|l|}
\hline \multicolumn{1}{|c|}{ Pregnancy Outcome } & \multicolumn{1}{c|}{ Number of Cases } \\
\hline Termination of pregnancy & $\begin{array}{l}10 \text { full (our case }[1,5,7,32,37, \\
39,40,46]) ;\end{array}$ \\
& 4 mosaic $[4,5,34,52]$ \\
\hline Intrauterine death & 1 mosaic $(1)$ \\
\hline Neonatal death & 3 full $[3,38,45]$ \\
\hline Survival past neonatal period & 1 mosaic $[3]$ \\
\hline Unknown & 2 full $[47,51] ;$ \\
& 1 mosaic $[38]$ \\
\hline
\end{tabular}

cases, still including the same plethora of phenotypic features (Table 3). The prenatally detected cases of tetrasomy $9 \mathrm{p}$ with lower levels of mosaicism presented with the involvement of only one organ system or without any major structural anomalies. One case presented with IUGR, the second with cardiac anomaly and the third with fetal ascites and hydrops fetalis. All mosaic cases were detected after amniocentesis $[1,4,5,33,34,38,52]$, with the lowest level of mosaicism being $15.8 \%$ [52] and the highest level of $96.7 \%$ [1].

Lastly, we were interested in gene dosage effect, therefore, prenatal cases of tetrasomy $9 p$ and trisomy $9 p$ were compared [53-56]. The clinical phenotype in trisomy $9 \mathrm{p}$ was similar to that described in tetrasomy $9 \mathrm{p}$ only milder.

Pregnancy outcome following PND of tetrasomy 9p were termination of pregnancy in $14 / 22$ cases (our case $[4,5,7,15,32,34,37,39,40,46,52])$, neonatal death $(3 / 22)$

Table 3. Prenatally detected (ultrasound assessment), abnormalities in the case of full tetrasomy $9 \mathrm{p}$ (full) and mosaic tetrasomy 9p (mosaic), according to the pregnancy trimester.

\begin{tabular}{|c|c|c|c|c|}
\hline Parameter & $\begin{array}{c}\text { First } \\
\text { Trimester }\end{array}$ & Second Trimester & Third Trimester & Unspecified Time \\
\hline CNS anomalies & - & $\begin{array}{l}6 \text { full }[7,15,32,37,39,45] ; \\
2 \text { mosaic }[5,33] \\
\end{array}$ & 2 full $[3,40]$ & 2 full $[38,47]$ \\
\hline Cardiac anomalies & - & \begin{tabular}{|l|}
2 full $[32,39]$ \\
1 mosaic $[52]$ \\
\end{tabular} & 1 full [40] & 1 mosaic $[48]$ \\
\hline IUGR & 1 full $[1]$ & \begin{tabular}{|l|}
2 full $[7,39] ;$ \\
2 mosaic $[5,33]$ \\
\end{tabular} & $\begin{array}{l}5 \text { full [3]; } \\
1 \text { mosaic [1] }\end{array}$ & $\begin{array}{l}5 \text { full }[38,46] \\
1 \text { mosaic }[4] \\
\end{array}$ \\
\hline Skeletal/limb anomalies & 2 full $[5,51]$ & 5 full (our case $[7,32,39,45]$ & $\begin{array}{l}1 \text { full }[40] ; \\
2 \text { mosaic }[1]\end{array}$ & \begin{tabular}{|l|}
1 full [47]; \\
1 mosaic [38] \\
\end{tabular} \\
\hline $\begin{array}{l}\text { Genitourinary tract } \\
\text { anomalies }\end{array}$ & - & $\begin{array}{l}\text { full (our case [32,37,39,45]; } \\
1 \text { mosaic [5] }\end{array}$ & 1 full [3] & 1 mosaic $[38]$ \\
\hline Facial dysmorphism & 1 full [5] & 4 full (our case $[7,39,45]$ ) & 1 full $[40]$ & 1 full [46] \\
\hline Cleft lip/palate & 2 full $[1,5]$ & 4 full (our case $[7,49,45]$ ) & - & $\begin{array}{l}3 \text { full }[38,46,47] ; \\
1 \text { mosaic }[38]\end{array}$ \\
\hline $\begin{array}{l}\text { Amniotic fluid volume } \\
\text { anomalies }\end{array}$ & - & 2 full $[7,39]$ & $\begin{array}{l}2 \text { full }[3,40] ; \\
1 \text { mosaic }[1]\end{array}$ & 1 full [46] \\
\hline Increased NT & \begin{tabular}{|l|}
4 full (our case \\
$[5,39,45])$
\end{tabular} & - & - & - \\
\hline
\end{tabular}

CNS: central nervous system; IUGR: intrauterine growth retardation; NT: nuchal translucency. 


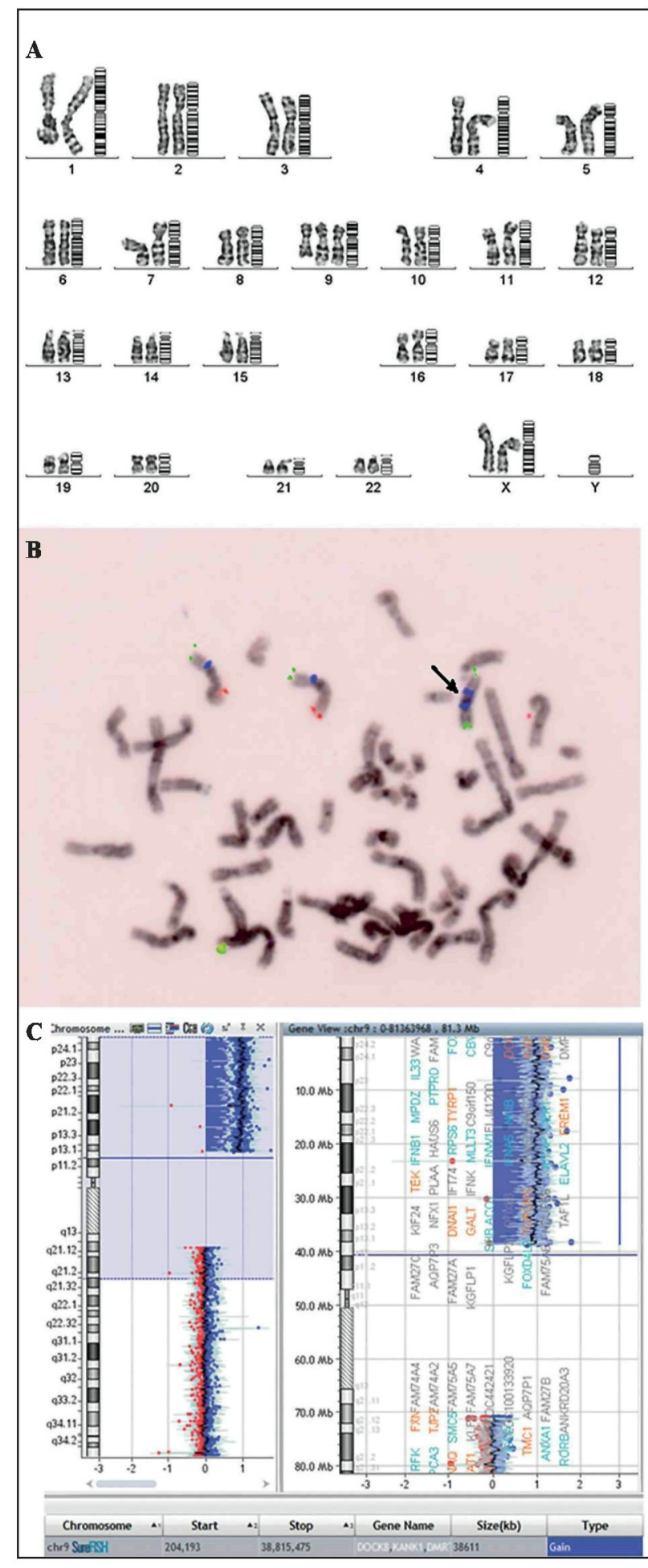

Figure 1. Prenatal genetic analysis reported additional cases of tetrasomy $9 \mathrm{p}$. (A) Fetal karyotype analysis revealed two normal chromosomes 9 and additional i(9p). (B) Fluorescent in situ hybridization using Vysis (Abbott Laboratories) probes: TelVyson 9p SG and TelVyson 9q SO and Vysis CEP 9 SAq. Isochromosome 9p is marked with an arrow. (C) Microarray analysis, revealing four copies of $9 \mathrm{p}$.
$[3,38,45]$, intrauterine death $(1 / 22)$ [1] and a child who survived to at least 4 years of age [33] (Table 4). For the remaining three cases this information was not provided. Only the mosaic forms of tetrasomy $9 p$ survive past the neonatal period, whereas full tetrasomy $9 p$ has a fatal outcome.

\section{DISCUSSION}

Herein we reviewed all previously published prenatal cases of tetrasomy $9 \mathrm{p}$ available in the PubMed database, and included our unpublished case. To the best of our knowledge, our case is the first prenatal case where the tetrasomy 9p presented with an increased NT of $4.1 \mathrm{~mm}$ as the only phenotypic finding during the first trimester ultrasound scan. Our case was detected early in pregnancy and therefore other abnormalities, commonly associated with tetrasomy $9 \mathrm{p}$, might not have been detected. Nevertheless, properly oriented counselling and early specific diagnosis provided sufficient information and support for the parents during their decision-making process.

Altogether, the most common prenatally detected features of tetrasomy $9 \mathrm{p}$ are CNS abnormalities (59\%), limb/ skeletal malformations (50.0\%), IUGR (45.0\%), cleft lip and/or palate (45.0\%). Additionally, facial dysmorphism, abnormality of the genitourinary system, abnormality of the amniotic fluid, and heart defects have also been described. This wide variability of clinical features in fetuses with tetrasomy $9 p$ (Tables 2 and 3 ) might be explained by the difference of a mosaic $v s$. nonmosaic forms, the level of mosaicism, a limitation of chromosomal anomaly to certain tissues, and the size of the isochromosome 9p and Hsa9 genes presented in four copies $[5,7,34,36,44]$.

The tissue-specific mosaicism was fully investigated in 5/7 prenatal mosaic cases $[4,5,33,34,52]$, and it was suggested that this chromosomal rearrangement is better tolerated in lymphocytes compared to fibroblasts, amniocytes or chorionic villi $(4,57)$, where the isochromosome was present with a lower frequency or not at all. Supporting this, there are considerably fewer cases of a mosaic form of tetrasomy 9 p reported prenatally in comparison to full tetrasomy $9 \mathrm{p}$. One might speculate that the loss of tetrasomy $9 p$ cells in the long-term culture of mosaic cases is the main reason. This is supported with a report of false-negative prenatal cases $[4,7,22,25,42]$. With the application of microarray technology uncultured cells are analyzed, providing significant advantage over classical cytogenetic techniques (faster turn-around time, no need for culturing and losing mosaic tetrasomy 9p). Another plausible explanation for lower detection rate 
of mosaic forms of tetrasomy $9 p$ might be a normal fetal ultrasound presentation of these cases during pregnancy $[7,22,25,42]$.

Interestingly, while comparing the trisomy $9 \mathrm{p}$ and tetrasomy 9p, we found that both syndromes have similar phenotype features but the clinical characteristics are much milder in trisomy $9 \mathrm{p}$ compared to tetrasomy $9 \mathrm{p}$. This might be due to additional copy number of the whole $9 p$ region in the tetrasomy $9 p$ cases, but further cases of prenatal trisomy $9 p$ need to be analyzed to make a conclusion.

Newer case reports of the tetrasomy $9 p$ used high throughput techniques such as a comparative genomic hybridization, which has the ability to define the break points more accurately, thus improving the understanding of the genotype-phenotype correlation. The severity of the tetrasomy $9 \mathrm{p}$ phenotype increases with the involvement of the $q$ arm; it was suggested that the presence of the $9 q$ arm in the tetrasomic cases is related to the severity of cardiac malformations, intellectual disability and death, but the review was based on a small number of cases and/or the use of cytogenetic techniques without precise mapping of the breakpoint in earlier cases (5). We identified only three non-mosaic tetrasomy $9 p$ prenatal cases that have been molecularly characterized by aCGH $[4,5,7]$, and involved the $9 q$ arm $[5,7]$. Of the three, only one case had an additional gene involved within the amplified region of the $\mathrm{q}$ arm [5], i.e., CNTNAP3 gene (contactin associated protein-like 3, OMIM610517). The protein encoded by this gene belongs to the family of cell-recognition molecules. The family represents a subgroup of the neurexins. Neurexins have a role in the CNS as cell-surface receptors and their presence is important in neurotransmission and synapse formation. The exact function of $C N T N A P 3$ remains to be determined [58].

There are still many factors to be elucidated that might play a role in the tetrasomy $9 \mathrm{p}$ phenotype; the contribution of each gene, a determination of the dosage-sensitive genes in 9p and/or 9q regions, the presence of presumably imprinted genes, a possible effect of the breakpoint on the disruption of gene regulation, and the unknown effect of involved non-coding regions. More cases discovered and characterized using genomic techniques and additional knowledge on the function of proteins involved will improve our understanding of the etiopathogenesis of the tetrasomy $9 \mathrm{p}$ disorder and offer the development of new therapeutic approaches.

Fetuses with increased NT measurements are at risk of having atypical chromosomal abnormalities in addition to the risk of common aneuploidies. Currently, noninvasive prenatal testing (NITP) is clinically validated for common aneuploidies only; these rare chromosomal abnormalities, such as tetrasomy $9 \mathrm{p}$, are not optimally detectable by NIPT.
A recent population study in Denmark revealed that among 193638 pregnancies that underwent invasive testing, $11 \%$ of foetuses had abnormal karyotype [59]. Of these, $23.4 \%$ phenotypically significant atypical chromosomal aberrations would be missed by currently available NIPT [59]. Therefore, the invasive diagnostic testing with high throughput techniques such as aCGH is still the gold standard for fetuses with ultrasound anomalies enabling rapid and definite diagnosis.

In conclusion, an accurate and fast delivered genetic diagnosis in the prenatal setting allows the parents informed decision making. A pre-testing genetic counseling with the parents undergoing invasive procedure and genetic testing should also include rare, but clinically no less important, genomic findings, in addition to the common chromosome aberrations. The ultrasound measurement of NT remains an important marker for chromosome abnormalities even in the non-invasive prenatal screening era. However, neither ultrasound assessment nor first trimester screening can propose a definite diagnosis of tetrasomy $9 \mathrm{p}$. The congenital anomalies of tetrasomy $9 p$ show a considerable clinical variation, and the same anomalies are common in fetuses with a broad range of chromosome abnormalities, including trisomy 13,18 and 21 . An invasive genetic test is still needed for accurate diagnosis of chromosomal anomalies, including tetrasomy $9 \mathrm{p}$.

Declaration of Interest. The authors report no conflicts of interest. The authors alone are responsible for the content and writing of this article.

\section{REFERENCES}

1. Dutly F, Balmer D, Baumer A, Binkert F, Schinzel A. Isochromosomes $12 p$ and $9 p$ : parental origin and possible mechanisms of formation. Eur J Hum Genet. 1998; 6(2): 140-144.

2. Ghymers D, Hermann B, Distèche C, Frederic J. Partial tetrasomy of number 9 chromosome, and mosaicism in a child with multiple malformations. [French] Humangenetik. 1973; 20(3): 273-282.

3. Schaefer GB, Domek DB, Morgan MA, Muneer RS, Johnson SF. Tetrasomy of the short arm of chromosome 9: Prenatal diagnosis and further delineation of the phenotype. Am J Med Genet. 1991; 15;38(4): 612-615.

4. Chen CP, Wang LK, Chern SR, Wu PS, Chen YT, Kuo YL, et al. Mosaic tetrasomy 9p at amniocentesis: Prenatal diagnosis, molecular cytogenetic characterization, and literature review. Taiwan J Obstet Gynecol. 2014; 53(1): 79-85. 
5. El Khattabi L, Jaillard S, Andrieux J, Pasquier L, Perrin L, Capri Y, et al. Clinical and molecular delineation of tetrasomy 9p syndrome: Report of 12 new cases and literature review. Am J Med Genet A. 2015; 167(6): 1252-1261.

6. Frémond ML, Gitiaux C, Bonnet D, Guiddir T, Crow YJ, de Pontual L, et al. Mosaic tetrasomy 9p: A Mendelian condition associated with pediatriconset overlap myositis. Pediatrics. 2015; 136(2): e544-e547.

7. Lazebnik N, Cohen L. Prenatal diagnosis and findings of tetrasomy 9p. J Obstet Gynaecol Res. 2015; 41(7): 997-1002.

8. Orye E, Verhaaren H, Van Egmond H, DevlooBlancquaertA. Anew case of the trisomy 9P syndrome. Report of a patient with unusual chromosome findings (46,XX/47,XX, $+\mathrm{i}(9 \mathrm{p})$ and a peculiar congenital heart defect. Clin Genet. 1975; 7(2): 134-143.

9. Rutten FJ, Scheres JM, Hustinx TW, ter Haar BG. A presumptive tetrasomy for the short arm of chromosome 9. Humangenetik. 1974; 25(3): 163-170.

10. Wisniewski L, Politis GD, Higgins JV. Partial tetrasomy 9 In a liveborn infant. Clin Genet. 1978; 14(3): 147-153.

11. Cavalcanti DP, Ferrari I, de Almeida JC, de Pina Neto JM, de Oliverira JA. Tetrasomy 9p caused by idic (9) (pter----q13----pter). Am J Med Genet. 1987; 27(3): 497-503.

12. Cuoco C, Gimelli G, Pasquali F, Poloni L, Zuffardi $\mathrm{O}$, Alicata $\mathrm{P}$, et al. Duplication of the short arm of chromosome 9. Analysis of five cases. Hum Genet. 1982; 61(1): 3-7.

13. Garcia-Cruz D, Vaca G, Ibarra B, Sánchez-Corona $\mathrm{J}$, Ocampo-Campos R, Peregrina S, et al. Tetrasomy 9p: Clinical aspects and enzymatic gene dosage expression. Ann Genet. 1982; 25(4): 237-242.

14. Moedjono SJ, Crandall BF, Sparkes RS. Tetrasomy 9p: Confirmation by enzyme analysis. J Med Genet. 1980; 17(3): 227-230.

15. McDowall AA, Blunt S, Berry AC, Fensom AH. Prenatal diagnosis of a case of tetrasomy 9p. Prenat Diagn. 1989; 9(11): 809-811.

16. Abe T, Morita M, Kawai K, Misawa S, Takino T, Hashimoto $\mathrm{H}$, et al. Partial tetrasomy 9(9pter to 9q2101) due to an extra iso-dicentric chromosome. Ann Genet. 1977; 20(2): 111-114.

17. Peters J, Pehl C, Miller K, Sandlin CJ. Case report of mosaic partial tetrasomy 9 mimicking Klinefelter syndrome. Birth Defects Orig Artic Ser. 1982; 18(3B): 287-293.
18. Balestrazzi P, Croci G, Frassi C, Franchi F, Giovannelli G. Tetrasomy 9p confirmed by GALT. J Med Genet. 1983; 20(5): 396-399.

19. Shapiro SD, Hansen KL, Littlefield CA. Brief clinical report: Non-mosaic partial tetrasomy and partial trisomy 9. Am J Med Genet. 1985; 20(2): 271-276.

20. Calvieri F, Tozzi C, Benincori $\mathrm{C}$, De Merulis MV, Bellussi A, Genuardi M, et al. Partial tetrasomy 9 in an infant with clinical and radiological evidence of multiple joint dislocations. Eur J Pediatr. 1988; 147(6): 645-648.

21. Andou R, Mimaki T, Ogihara T, Tamai H, Mino M. A case of tetrasomy 9p. Acta Paediatr Jpn. 1994; 36(6): 724-726.

22. Eggermann T, Rossier E, Theurer-Mainka U, Backsch $\mathrm{C}$, Klein-Vogler U, Enders H, et al. New case of mosaic tetrasomy $9 \mathrm{p}$ with additional neurometabolic findings. Am J Med Genet. 1998; 75(5): 530-533.

23. Jalal SM, Kukolich MK, Garcia M, Benjamin TR, Day DW. Tetrasomy 9p: An emerging syndrome. Clin Genet. 1991; 39(1): 60-64.

24. Leichtman LG, Zackowski JL, Storto PD, Newlin A. Non-mosaic tetrasomy $9 p$ in a liveborn infant with multiple congenital anomalies: Case report and comparison with trisomy 9p. Am J Med Genet. 1996; 63(3): 434-437.

25. Grass FS, Parke JC Jr, Kirkman HN, Christensen V, Roddey OF, Wade RV, et al. Tetrasomy 9p: Tissuelimited idic(9p) in a child with mild manifestations and a normal CVS result. Report and review. Am J Med Genet. 1993; 47(6): 812-816.

26. Melaragno MI, Brunoni D, Patrício FR, Corbani M, Mustacchi Z, dos Santos Rde C, et al. A patient with tetrasomy 9p, Dandy-Walker cyst and Hirschsprung disease. Ann Genet. 1992; 35(2): 79-84.

27. Nakamura Y, Sato E, Sakai K, Sakuma S, Hashimoto T, Sindou S. Abnormal chromosome 9 in a neonate program. Report of three cases. Arch Pathol Lab Med. 1990; 114(2): 185-187.

28. Papenhausen P, Riscile G, Miller K, Miller K, Kouisseff B, Tedesco T. Tissue limited mosaicism in a patient with tetrasomy 9p. Am J Med Genet. 1990; 37(3): 388-91.

29. Park JP, Rawnsley BE, Marín-Padilla M. Tetrasomy 9p syndrome. Ann Genet. 1995; 38(1): 54-56.

30. Stumm M, Tönnies H, Mandon U, Götze A, Krebs P, Wieacker PF. Mosaic tetrasomy $9 p$ in a girl with multiple congenital anomalies: Cytogenetic and molecular-cytogenetic studies. Eur J Pediatr. 1999; 158(7): 571-575. 
31. Tonk VS. Moving towards a syndrome: Areview of 20 cases and a new case of non-mosaic tetrasomy $9 \mathrm{p}$ with long-term survival. Clin Genet. 1997; 52(1): 23-29.

32. Van Hove J, Kleczkowska A, De Bruyn M, De Bruyn M, Bekaert J, Fryns JP. Tetrasomy 9p: prenatal diagnosis and fetopathological findings in a second trimester male fetus. Ann Genet. 1994; 37(3): 139142.

33. Cazorla Calleja MR, Verdú A, Félix V. Dandy-Walker malformation in an infant with tetrasomy 9p. Brain Dev. 2003; 25(3): 220-223.

34. Chen CP, Chang TY, Chern SR, Lee CC, Town DD, Lee MS, et al. Prenatal diagnosis of low-level mosaic tetrasomy $9 \mathrm{p}$ by amniocentesis. Prenat Diagn. 2007; 27(4): 383-385.

35. Coman D, Bacic S, Boys A, Sparrow DB, Dunwoodie $\mathrm{SL}$, Savarirayan $\mathrm{R}$, et al. Spondylocostal dysostosis in a pregnancy complicated by confined placental mosaicism for tetrasomy $9 \mathrm{p}$. Am J Med Genet A. 2008; 146A(15): 1972-1976.

36. de Azevedo Moreira LM, Freitas LM, Gusmão FA, Riegel M. New case of non-mosaic tetrasomy $9 \mathrm{p}$ in a severely polymalformed newborn girl. Birth Defects Res A Clin Mol Teratol. 2003; 67(12): 985-988.

37. Deurloo KL, Cobben JM, Heins YM, de Ru M, Wijnaendts LC, van Vugt JM. Prenatal diagnosis of tetrasomy $9 p$ in a 19-week-old fetus with DandyWalker malformation: A case report. Prenat Diagn. 2004; 24(10): 796-798.

38. Dhandha S, Hogge WA, Surti U, McPherson E. Three cases of tetrasomy 9p. Am J Med Genet. 2002; 113(4): 375-380.

39. di Vera E, Liberati M, Celentano C, Calabrese G, Guanciali-Franchi PE, Morizio E, et al. Rhombencephalosynapsis in a severely polymalformed fetus with non-mosaic tetrasomy 9p, in intracytoplasmic-sperm-injection pregnancy. J Assist Reprod Genet. 2008; 25(11-12): 577-580.

40. Hengstschläger $M$, Bettelheim D, Drahonsky R, Repa C, Deutinger J, Bernaschaek G. Prenatal diagnosis of tetrasomy 9p with Dandy-Walker malformation. Prenat Diagn. 2004; 24(8): 623-626.

41. Henriques-Coelho T, Oliva-Teles $\mathrm{N}$, Fonseca-Silva ML, Tibboel D, Guimarães H, Corriea-Pinto J. Congenital diaphragmatic hernia in a patient with tetrasomy 9p. J Pediatr Surg. 2005; 40(10): e29-e31.

42. Lloveras E, Pérez C, Solé F, Zamora L, Lladonosa A, Espinet B, et al. Two cases of tetrasomy 9p syndrome with tissue limited mosaicism. Am J Med Genet A. 2004; 124A(4): 402-406.
43. McAuliffe F, Winsor EJ, Chitayat D. Tetrasomy 9p mosaicism associated with a normal phenotype. Fetal Diagn Ther. 2005; 20(3): 219-222.

44. Ogino W, Takeshima $Y$, Nishiyama A, Yagi $\mathbf{M}$, Oka N, Matsuo M. Mosaic tetrasomy 9p case with the phenotype mimicking Klinefelter syndrome and hyporesponse of gonadotropin-stimulated testosterone production. Kobe J Med Sci. 2007; 53(4): 143-50.

45. Nakamura-Pereira M, Cima LC, Llerena JC Jr, Guerra FA, Peixoto-Filho FM. Sonographic findings in a case of tetrasomy $9 \mathrm{p}$ associated with increased nuchal translucency and Dandy-Walker malformation. J Clin Ultrasound. 2009; 37(8): 471-474.

46. Tan YQ, Chen XM, Guan XY, Lu GX. Prenatal diagnosis of nonmosaic tetrasomy $9 p$ by microdissection and FISH: Case report. Chin Med J. [English] 2007; 120(14): 1281-1283.

47. Tang W, Boyd BK, Hummel M, Wenger SL. Prenatal diagnosis of tetrasomy 9p. Am J Med Genet A. 2004; 126A(3): 328.

48. Baronchelli S, Conconi D, Panzeri E, Bentivegna A, Redaelli S, Lissoni S, et al. Cytogenetics of premature ovarian failure: An investigation on 269 affected women. J Biomed Biotechnol. 2011; 2011(4): 370195. doi: 10. 1155/2011/370195.

49. Chen CP, Lin SP, Su JW, Lee MS, Wang W. Phenotypic features associated with mosaic tetrasomy $9 p$ in a 20-year-old female patient include autism spectrum disorder. Genet Couns. 2012; 23(2): 335-338.

50. Papoulidis I, Kontodiou M, Tzimina M, Saitis I, Hamid AB, Klein E, et al. Tetrasomy 9p mosaicism associated with a normal phenotype in two cases. Cytogenet Genome Res. 2012; 136(4): 237-241.

51. Podolsky R, Saltzman D, Auerbach M, Roman AS. Absent nasal bone as a marker of tetrasomy $9 \mathrm{p}$. Prenat Diagn. 2011; 31(13): 1313.

52. Wang H, Xie LS, Wang Y, Mei J. Prenatal diagnosis of mosaic tetrasomy $9 \mathrm{p}$ in a fetus with isolated persistent left superior vena cava. Taiwan J Obstet Gynecol. 2015; 54(2): 204-205.

53. Sherer DM, Abramowicz JS, Jaffe R, Woods JR Jr. Cleft palate: Confirmation of prenatal diagnosis by colour Doppler ultrasound. Prenat Diagn. 1993; 13(10): 953-956.

54. Chen CP, Chang TY, Shih JC, Lin SP, Lin CJ, Wang $\mathrm{W}$, et al. Prenatal diagnosis of the Dandy-Walker malformation and ventriculomegaly associated with partial trisomy $9 \mathrm{p}$ and distal $12 \mathrm{p}$ deletion. Prenat Diagn. 2002; 22(12): 1063-1066. 
55. Hengstschläger $M$, Bettelheim $D$, Repa $C$, Lang $S$, Deutinger J, Bernaschek G, et al. A fetus with trisomy $9 p$ and trisomy $10 p$ originating from unbalanced segregation of a maternal complex chromosome rearrangement $t(4 ; 10 ; 9)$. Fetal Diagn Ther. 2002; 17(4): 243-246.

56. Kasakyan S, Lohmann L, Aboura A, Quimsiyeh M, Menezo Y, Tachdjian G, et al. De novo complex intra chromosomal rearrangement after ICSI: Characterisation by BACs micro array-CGH. Mol Cytogenet. 2008; 1: 27.

57. Shehab MI, Mazen I, Bint S. Tissue-specific mosaicism for tetrasomy 9 p uncovered by array CGH. Am J Med Genet A. 2011; 155A(10): 2496-2500.
58. Qiao YQ, Huang ML, Zheng Q, Wang Tr, Xu AT, Cao $\mathrm{Y}$, et al. CNTNAP3 associated ATG16L1 expression and Crohn's disease. Mediators Inflamm. 2015; 2015(1): 404185. doi: 10.1155/2015/404185.

59. Petersen OB, Vogel I, Ekelund C, Hyett J, Tabor A. Potential diagnostic consequences of applying noninvasive prenatal testing: Population-based study from a country with existing first-trimester screening. Ultrasound Obstet Gynecol. 2014; 43(3): 265-271. 